Helena Casas Perpinyà

\title{
Dones en presència a l'Època Medieval. Proposta per a una epistemologia històrica de la llibertat femenina
}

Durant els dies en el quals estava escrivint aquest article, vaig quedar amb una companya, artista i feminista històrica i membre de la Comunità Filosofica Diotima, Donatella Franchi. Amb ella parlàvem sobre la seva gran passió, l'art i la creació femenina. M'explicava com als anys 80 havia descobert la presència històrica de dones artistes a la seva ciutat, Bolonya, i com la trobada amb Lavinia Fontana, pintora del segle XVI, havia suposat un canvi en la seva investigació artística, sempre lligada a la política de la quotidianitat. "Per mi tot passa per les dones - em va dir - i per això és tan important recuperar i reconstruir les genealogies femenines de la història”.

Paradoxalment, jo que treballo amb la història, fa poc mai havia pensat que l'experiència femenina fos un element que es pogués posar en joc en l'estudi del nostre passat. L'experiència femenina en la història, que quan parla ens adonem que té molt a veure amb la llibertat de les dones, és un fil històric que he identificat en l'escriptura femenina medieval. Però per treballar-la, per treballar les fonts literàries femenines, i no tant literàries perquè a l'escriure es perd el cos i a vegades és necessària la ficció per suplir-lo, ens hem de plantejar quina és l'epistemologia i quina és la metodologia que fem servir. Parlo de mètode, entenent-lo com el que és: un camí en moviment. Un mètode que:

no separa la historia de la historiadora de la historia que la historiadora escribe, como ya no separamos, ni al hablar ni al estudiar la lengua, el significante del significado, dejando caer así de paso el estructuralismo lingüístico, que construye una antinomia de lo que no lo es. ${ }^{1}$

Amb aquestes paraules parla María Milagros Rivera de la Pratica della Storia Vivente, un projecte que neix el 2005 a la Libreria delle Donne di Milano de la mà d'una comunitat d'historiadores feministes que practiquen l'escriptura femenina de la història. La Storia Vivente és una pràctica, una via lliure per escriure història en relació i que posa en comú les experiences femenines, no cancel·la l'amor, sinó que el situa amb la història al centre de la història. La definició cartesiana

1 M. M. Rivera y Garretas, "Prólogo. La semilla de un método viviente”, in L. Minguzzi L. Tavernini - M. Santini, La Pratica della Storia Vivente, in “DWF”, 95/3, 2012, pp. 1-7 (p. 2).

Helena Casas Perpinyà, Universitat de Barcelona

Ә Open Access. (C) 2018 Helena Casas Perpinyà, published by De Gruyter. (c) BY-NC-ND This work is licensed under the Creative Commons Attribution-NonCommercial-NoDerivatives 4.0 License. https://doi.org/10.1515/9783110596755-013 
del mètode, que no prendrà mai el fals per la veritat, resta endarrera. Es tracta d'un recorregut diferent, no pas contrari a aquell de l'objectivitat. Reinventar un llenguatge que no cancel-li la llibertat femenina en la història s'ha desvelat com a condició sine qua non per traçar el mètode. Meta i hodos, més enllà del camí. Conèixer les vies, com es proposà Hildegarda de Bingen amb el seu llibre Scivias (1141), constitueix una pràctica viva, mòbil, que posa en joc la transformació; una etimologia de les paraules que reconeix un moviment teòric rigorosament allunyat de l'estaticitat acadèmica. ${ }^{2}$

L'epistemologia de la llibertat femenina és doncs aquella que parteix del lliure femení com a premissa històrica i de la mateixa llibertat femenina com a pràctica política de la relació. És en aquest punt en el qual es desmunta el llenguatge neutre que esterilitza la política sexual i amb el qual resulta molt difícil treballar les trobairitz des de la diferència sexual ${ }^{3}$ i esdevé quasi impossible comprendre Marie de France. Ella, escriptora en llengua anglonormanda, la identitat de la qual és encara discutida, escrigué en el segle de l'eclosió de l'escriptura femenina. El Pròleg del seus Lais és una declaració d'intencions i ella, la que "mai serà oblidada"4 reivindica la pròpia escriptura com un do que li ha estat atorgat. En aquest sentit, no m'interessa la comparativa textual entre l'escriptura femenina i la masculina, sinó la política sexual que hi podem trobar, entenent que és també política.

Voldria prendre l'expressió del punt d'Arquímedes de la historiadora Paola Di Cori, al respecte de la "naturalesa amfíbia de la història", 5 ja que en ella reconec i em reconcilio amb un cert malestar simbòlic a l'hora d'escriure i llegir la història. Aquesta és la conjunció de dos universos que conviuen desordenadament en contemporani, "dos universos distintos que no es posible escindir pero entre los cuales a menudo no logramos ni percibir ni establecer vínculos". ${ }^{6}$ Dos universos, el masculí i el femení, que es relacionen amb el món de manera diversa i que, evidentment, no ocupen el mateix espai a l'scriptorium.

2 Dec aquestes reflexions a les intervencions de María Milagros Rivera y Garretas i Marirì Martinengo que tingueren lloc al Convegno della Pratica della Storia Vivente el passat 10 de març a la Libreria delle Donne di Milano l'any 2016.

3 Un estudi dedicat a les Trovadores des de la diferència sexual el trobem en M. Martinengo, Le Trovatore. Poetesse dell'amor cortese, Milà, Quaderni di Via Dogana, Libreria di Donne di Milano, 1996.

4 “Oëz, seignurs, ke dit Marie / Ki en sun tens pas ne s’oblie” (Guigemar, vv. 4-5). María de Francia, Los Lais, edición bilingüe, Madrid, Editora Nacional, 1975.

5 P. di Cori, Dalla storia delle donne alla storia di genere, in "Rivista di Storia Contemporanea", 4, 1987, pp. 548-559 (p. 107).

6 Ibid., p. 108. 
La Història de les Dones, que ens ha dut la revolució femenina, que ha protagonitzat el segle XX, sembla presentar les dones com a subjectes històrics, "sujetas, por lo tanto", 7 emmarcades en una referencialitat masculina pròpia dels estudis de gènere ${ }^{8}$ que, a la recerca de la paritat, construeixen un relat històric basat en l'excepcionalitat femenina en la història. Perquè les dones, sostenidores de la vida i reproductores de la història, seguirem essent excepcionals si "estar en la historia significa haber entrado en una cierta inmortalidad que separa a los héroes del resto de los mortales". 9

No voldria, doncs, que la Història de les Dones fos tan sols nascuda per constrastar l'epistemologia clàssica de la història, sinó per generar nous espais de creació de pensament femení, capaços de considerar les singularitats històriques que travessen la diferència sexual.

En un intent de restituir la història a les dones i les dones a la història ${ }^{10}$ la historiografia de les dones ha emprat totes les eines i metodologies de les quals disposaven els historiadors, obrint-se pas en un paradigma historiogràfic que no preveia espai per a la llibertat femenina. Aquesta és la raó per la qual les dones, historiadores i historiades, ${ }^{11}$ semblem romandre encara avui dissoltes en l'esterilitat del coneixement universitari, fent referència a aquella potencial fertilitat que Anna Piussi veu fosa en el fet que "la antigua voluntad de excluir a las mujeres va siendo sustituida por el esfuerzo de incluirlas por todos los medios". ${ }^{12}$

A la pregunta que Gisela Bock celebrà ésser aleshores resposta, "existeix una història de les dones?"13 jo afegiria, avui, com podem treballar la llibertat femenina a l’Ėpoca Medieval, sinó és reconeixen l'autoritat entre dones?

7 J. Lorenzo Arribas, El telar de la experiencia. Historia de las mujeres y epistemología feminista, in M. Santo Tomás, La Historia de las mujeres: una revisión historiográfica, Valladolid, Universidad de Valladolid, 2004, pp. 73-92, p. 78.

8 És important no oblidar que la Teoria dels Gèneres nasqué fora dels àmbits acadèmics vinculats a la segona onada del feminisme del segle XX. Fruit de l'impuls científic de diversos científics gais, pertanyents a diferents universitats nordamericanes, els estudis de gènere troben el seu origen en el qüestionament masculí dels estereotips virils des de l'homosexualitat. Al respecte vegeu M. Rivera y Garretas, Nombrar el mundo en femenino. Pensamiento de las mujeres y teoría feminista, Barcelona, Icaria, 1994.

9 M. Zambrano, Para una historia de la piedad, Málaga, Torre de las Palomas, 1989, p. 103.

10 G. Bock, Women's History and Gender History: Aspects of an International Debate, in "Gender\&History", 1, 1989, pp. 7-30.

11 J. Lorenzo Arribas, El telar de la experiencia, cit., p. 78.

12 A.M. Piussi - R. Arnaus, La universidad fértil. Mujeres y hombres, una apuesta política, Barcelona, Octaedro, 2001, p. 146.

13 G. Bock, Women's History and Gender History, cit. 
En els nostres dies i, assistint a la fi del patriarcat, ${ }^{14}$ les dones hem entès que "nuestra existencia social libre no depende de lo que los hombres sean o dejen de ser". ${ }^{15}$ Una de les grans herències que hem rebut de la història del feminisme, és que ens ha descobert la llibertat d'aquelles coses que pensàvem no lliures: altrament, la llibertat femenina no hauria estat mai una realitat històrica. ${ }^{16}$ Parlo de la llibertat femenina que, en el seu moment, fou una revolució simbòlica i a la que Lia Cigarini ${ }^{17}$ posà nom. Una llibertat que no es pot reduir a la legalitat o a les estructures institucionals, sinó que té a veure amb l'autonomia de la mesura masculina, amb la subversió de les coordenades del poder a través de les relacions entre dones, relacions que, com l'espiritualitat i els models de vida de les beguines, tenen a veure amb la política sexual. ${ }^{18}$ Quan aquesta llibertat és aplicada a la història l'error d'epistemologia és palès en l'exigència d'un canvi de mirada: perquè partir de si no és una categoria ni un paradigma encasellable.

En aquest sentit, considero que el centre del debat s'ha desplaçat de la pròpia significació de la Història de les Dones. Natalie Zemon Davis afirmava el 1975 que:

Me parece que deberíamos interesarnos tanto en la historia de las mujeres como de los hombres, que no deberíamos trabajar solamente sobre el sexo oprimido, del mismo modo que un historiador de las clases sociales no puede centrarse por entero en los campesinos. ${ }^{19}$

Això no obstant, considero que, a dia d'avui i 42 anys després, la qüestió és de caràcter simbòlic, rau en com es trasllada l'experiència femenina en el mètode històric. És a dir, en reformular-nos la pregunta de com la Història de les Dones es relaciona amb la història ${ }^{20}$ havent entès que els sexes són dos i la política sexual és, per tant, composta per relacions asimètriques que poden ésser concebudes des de la diferència sexual com epistemologia.

14 Em remeto aquí a les reflexions exposades a l'obra col-lectiva F. Graziani, El final del patriarcado: ha ocurrido y no por casualidad, Milà, Sottosopra, 1998.

15 L. Muraro, Hacer política, escribir historia (notas de trabajo), in "DUODA Papers de Treball”, 2, 1991, pp. 87-97 (p. 95).

16 Aquesta és una reflexió sorgida en un dels debats del Seminari "Filosofia en práctica y presencia” amb Chiara Zamboni, celebrat al Circolo della Rosa de Verona al maig del 2016 en el marc del Màster d'Estudis de la Diferència Sexual de la Universitat de Barcelona.

17 Vid. L. Cigarini, La política del deseo, Barcelona, Icaria, 1996.

18 Vid. L. Cigarini, Libertad relacional, in "Revista de Estudios de la Diferencia Sexual DUODA", 26, 2004, pp. 85-11; L. Cavaliere - L. Cigarini, Hay una buena diferencia, Barcelona, Biblioteca Virtual de Investigación y Docencia DUODA, 2016.

19 N. Zemon Davis, Womens History in Transition: The European Case, in "Feminist Studies", 3, 1975, pp. 83-103 (p. 90).

20 G. Bock, Women's History and Gender History, cit. 
Certament les definicions esdevenen necessàries en la taxonomia epistemològica, però si "los conceptos son abstracciones a partir de un mundo de realidades tangibles"21 la política sexual no pot romandre exclosa de les nostres consideracions i interpretacions de les fonts medievals. Allò que Michel Foucault considerà com "els espais de comunicación"22 al respecte de la definició dels conceptes, resta inoperatiu per l'escriptura històrica si, als paràmetres de temps, espai i grups socials, sempre segons Foucault, no es considera el cos sexuat dels subjectes històrics. A dia d'avui, doncs, les ciències socials que en el seu moment impulsaren l'estudi de les implicacions dels cos en les seves diverses etapes històriques, es manifesten insuficients a l'hora de desenvolupar un discurs que es reconciliï amb l'ordre simbòlic de la mare. ${ }^{23}$

Com March Bloch, jo tampoc voldria separar la història de les seves entranyes, com tampoc voldria mutilar-la ${ }^{24}$ de la seva sensibilitat i la seva sexuació. El que s'ha treballat des de la historiografia del medievalisme social i antropològic com les tècniques del $\cos ^{25}$ ha tendit a una objectivització dels conceptes, estudiant el cas de les dones a mode de monogràfic o capítol singular d'un compendi general.

Així com Fernand Braudel ${ }^{26}$ advertí sobre la desatenció de la història respecte a la geografia, com si la vida no tingués espai i aquest no intervingués en la reproducció humana, sembla que ara ens trobem davant una altra inadvertència: com és possible treballar el cos sense tenir en compte la diferència sexual?.

És només en aquest buit conceptual, que es deixa entreveure una de les mancances primordials de la nostra historiografia, en el qual la Teoria del Gènere sí que resulta operativa, ja que el gènere no és sexuable, en tant que categoria social i política.

Al respecte d'aquesta mancança interpretativa, els filòsofs i sociòlegs Max Horkheimer i Theodor Wiesengrund, sense fer referència a la política sexual però parlant de la mateixa història inconscient, que segons Braudel és més percebuda del que ens atrevim a reconèixer, ${ }^{27}$ parlen de les dues històries d'Europa, una,

$21 \mathrm{H}$. Kleinschmidt, Understanding the Middle Ages: The transformations of Ideas and the Attitudes in the Medieval World, Londres, Boydel \& Brewer, 2000, p. 7.

22 M. Foucault, Arqueología del saber, Madrid, Siglo XXII, 1999.

23 Vid. L. Muraro, El orden simbólico de la madre, Madrid, Horas y Horas, 1994.

24 M. Bloch, La sociedad feudal, Madrid, Akal, 1988.

25 J. Le Goff - N. Troung, Une histoire du corps au Moyen Age, París, Poche, 2006.

26 F. Braudel, Histoire et sciences sociales: La longue durée, in "Annales. Histoire, Sciences Sociales”, 13/4, 1958, pp. 7-37.

27 Ibid. 
documentada i escrita, l’altra subterrània. La segona és constituïda pel destí dels instints i de les passions humanes preses, desnaturalitzades de la civilització. ${ }^{28}$

Aquesta és la mateixa Europa que ha estat substanciada, segons Jean-Claude Schmitt, per la implicació política del cos en la creació de les estructures ideològiques i institucionals des del segle V. ${ }^{29}$ Perquè el cos a l'Ėpoca Medieval juga un paper central en el desenvolupament de la política i la ideologia i no és pas casualitat que l'únic investigador de l'École des Annales avessat a l'estudi del cos fos precisament un medievalista, Marc Bloch. ${ }^{30}$

Però existeix l'element interpretatiu pel qual no es pren en consideració la sexuació del cos, o millor dit, no existeix aquell element simbòlic que té en compte la diferència sexual. És a dir, l'economia i la política són enteses com un tot neutre i imparcial, una maquinària produïda gràcies a l'esforç, l'explotació i el plaer dels cosssos, sobre la qual la historiografa marxista ha construït el seu pes teòric. L'asimetria sexual travessa, no obstant això, estructures i categories en tant que la política sexual és anterior a qualsevol política, ${ }^{31}$ per la qual existeix “otra economia y una política que no están significadas por el dinero y por el poder. Están significadas por el don: el don del cuerpo y de la lengua, la lengua que llamamos precisamente materna”. ${ }^{32}$

L'estructura tradicional de la Història en termes binaris sembla haver consolidat una idea dialèctica dels sexes: home-dona és, per a gran part de la historiografia, un binomi de contraris, per tant, una relació de conceptes definits per l'aval social i polític que la Teoria del Gènere ha identificat en el patriarcat, com a únic fenomen històric productor i lector de les relacions entre els sexes. ${ }^{33} \mathrm{Un}$ punt de partida pel qual la Història Social no considera possible la vida més enllà

28 M. Horkheimer, Dialettica dell'Illuminismo, Torino, Giulio Enaudi, 1966.

29 J. Schmitt, Le corps, les rites, les rêves, le temps: Essais d'anthropologie médiévale, Paris, Gallimard, 2001.

30 J. Le Goff - N. Troung, Une histoire du corps au Moyen Age, cit.

31 C. Pateman, El contrato sexual, Barcelona, Anthropos, 1995.

32 M. Rivera y Garretas, Vivir el cuerpo como un don, in "Revista de Estudios de la Diferencia Sexual DUODA", 37, 2009, pp. 31-46 (p. 7).

33 Faig referència aquí a la diferència que planteja María Milagros Rivera entre "relacions entre els sexes" i "relacions dels sexes". Els homes i les dones ens relacionem des de que neixem i ho fem al llarg de la nostra vida, en funció de les circumstàncies, les necessitats i els gustos. Aquesta és la relació entre els sexes, una relació amb unes finalitats determinades, en moments determinats . En canvi, la relació dels sexes té a veure amb les reflexions de cadascú del sentit lliure de ser homes i del sentit lliure de ser dones i la relació que s'estableix entre elles; el que seria una revolució simbòlica. Vegeu María Milagros Rivera a Signos de libertad femenina (en diálogo con la historia y la política masculinas, Barcelona, Biblioteca Virtual de Investigación y Docencia DUODA, 2012. 
dels marges polítics i socialment preestablerts, allà on precisament la llibertat femenina floreix perquè, si una cosa ens ensenya el simbòlic femení en la història és que el patriarcat no n'ha ocupat mai tots els espais d'aquesta. És, per tant, imprescindible "sottolineare che non tutte le definizioni sono intercambili" ${ }^{34}$ una afirmació que espero que aporti llum al debat que discuteix sobre gènere, diferència sexual i feminitat en la història. Considero que, si bé no és impossible, esdevé molt complicat reconstruir genealogies femenines sense replantejar-nos aquest debat. Tant és així que ens costa molt entreveure les conexions i les transmissions del saber per no estar estrictament escrites.

Aquests és el cas de les trobairitz, les anomenades mestres de la civilització. En els primers segles de l'any mil, la vida de les ciutats i de les corts d'Occitània es caracteritzà per una intensa activitat de vincles i de relaciones, a través de les quals homes i dones, no tan sols de classe alta, inventaren i augmentaren formes d'art originals en una llengua que fonamentarien tota la cultura a Europa: "Sin la linfa occitana, cuyo componente básico fue el amor, Europa no existiría”. ${ }^{35} \mathrm{La}$ poesia de les trovadores és un exemple d'expressió i d'actuació, explicitant la seva diferència, posant de manifest el propi eros, amb la llibertat femenina de no fer el que fan els homes. En l'estructuració d'aquesta civilització, les dones jugaren un paper d'autoritat, convertint-se en models de comportament i de referència, generoses mecenes, artistes i senyores feudals.

Treballar per civilitzar la societat, escriure i parlar de com desitgen ser estimades; prenent l'amor com a element ordenador de la societat. Segles després les Precioses parlaran també d'amor en autoritat i crearan una nova manera de fer política als seus Salons. Mestres també elles de la civilització, són exemple d'aquest transcórrer en els segles a través de la llibertat femenina.

Quan María Zambrano parlà sobre el sentir del coneixement històric ${ }^{36}$ inicià $^{-}$ per la poesia dels primers temps: La Ilíada i l'Odissea, la part més extraordinària de la història per no ésser certa. Aquella que, malgrat la incertesa, aconsegueix crear la història dels anònims mortals: aquella que és contada a les novel-les. Per aquesta raó, considera Zambrano, la novel·la - i aprofitant l'avinentesa, jo afegiria els epistolaris femenins medievals - com la millor història i la millor filosofia, perquè ens parlen de les formes de vida. Probablement sigui cert que "en la novel·la y en la poesía hay algo más", ${ }^{37}$ allò que no es pot objectivar, perquè "el deseo femenino no se objetiva. O está vivo o desaparece de la historia. No crea

34 P. di Cori, Dalla storia delle donne alla storia di genere, cit.

35 M. Martinengo - M. Giraud, La herencia de las trovadoras: de las trovadoras a las preciosas, in "Revista de Estudios de la Diferencia Sexual DUODA", 39, pp.19-32 (p. 20).

36 M. Zambrano, Para una historia de la piedad, Málaga, Torre de las Palomas, 1989, p. 103. 37 Ibid. 
instituciones, jerarquías, poder, o conceptos sobre la libertad y la democracia sea o no representativa - que valgan durante siglos". ${ }^{38}$

Probablement, doncs, per copsar la Història de les Dones esdevé urgent alliberar-se de la història, ${ }^{39}$ fer aquell pas enrera que em permeti observar les coses des de fora, aquell femení provenir de afuera del que parla Hélène Cixous. ${ }^{40}$ Perquè si "la mujer debería reecontrarse, entre otras formas, a través de las imágenes de ella ya depositadas en la historia y las condiciones de producción de la obra del hombre, y no a partir de su obra, su genealogia" ${ }^{41}$ el primer pas consisteix en identificar la neutralitat i sexuar-la, com qui posa el mirall de cara al món.

Renunciar, però, a la metodologia tradicional, clàssica, a l'autoritarisme metòdic ${ }^{42}$ no significa treballar la història havent llençat a la brossa tot allò que l'ha concebuda tal i com la coneixem avui, sinó d'ésser capaces d'introduir un debat permanent en termes historiogràfics. Un debat regit per l'autoritat entre dones i conduït per l'intercanvi i la relació, "esserci anche con delle altre poiché abbiamo bisogno di un rifferimento simbolico", ${ }^{43}$ ja que el sentit de la diferència feminista i femenina té a veure amb la nostra història, en tant que dones i en tant que història del món.

“Todo, todo lo que puede ser objeto de conocimiento, todo lo que puede ser sujeto a experiencia, querido o calculado, es previamente sentido de algún modo". ${ }^{44}$ És aixi com, intentant no separar la història de l'escriptura de la història, aquesta és una aposta que va més enllà de la proposta epistemològica per instal-lar-se en la comprensió política de les relacions a dins la Universitat. És a dir, donar sentit polític a l'autoritat creada entre dones que estudien, investiguen i ensenyen l'escriptura de la història, aquella escriptura del passat viu de la que es participa, de la qual se'n prèn partit. La maestría de libertad que Diana Sartori propasa amb l'aposta de “volver a pensar, con otras, en lo que hacemos" ${ }^{45}$, recuperant Hannah Arendt.

38 L. Cigarini, La politica del deseo, cit.

39 J. Lorenzo, El telar de la experiencia, cit., p. 78.

40 H. Cixous, Entre l'ecriture, París, Des femmes, 1986.

41 L. Irigaray, Ética de la diferencia sexual, Barcelona, Icaria, 2010, p. 39.

42 L. Muraro, Hacer política, escribir historia, cit., p. 95.

43 D. Sartori, Volver a pensar, con otras, en lo que hacemos, XI Dialogo Magsitral de DUODA al maig del 2016 a la Universitat de Barcelona. Vegeu: [http://www.ub.edu/ubtv/video/dianasartorivolver-a-pensar-con-otras-en-lo-que-hacemos] [consulta 21/12/2016].

44 M. Zambrano, Para una historia de la piedad, cit. p. 107.

45 Recupero el títol de la conferència de Diana Sartori, celebrada durant el XI Diálogo Magsitral de DUODA al maig del 2016 a la Universitat de Barcelona. Vegeu: [http://www.ub.edu/ubtv/ video/dianasartori-volver-a-pensar-con-otras-en-lo-que-hacemos] [consulta 23/12/2016]. 
En l'aposta per la història, en l'Acadèmia, en l'escriptura "somos pocas pero bastantes". Jo també penso que "la escritura es una fiesta del significante" ${ }^{46} \mathrm{i}$ que, de la mateixa manera com passa amb la historiografia i la seva història, "el significante único es el opio del texto". ${ }^{47}$

L'epistemologia de la llibertat femenina podria ser "il cartello che informa le persone che cercano il posto ma non sanno l'indirizzo", ${ }^{48}$ una ocasió perfecta per recordar el títol del llibre de Diotima que augura un futur esperançador a la llibertat femenina, a partir d'allò que la creativitat de les dones ha estat capaç de fer florir també a l'Ėpoca Medieval: La Festa è qui. ${ }^{49}$

46 H. Cixous, Entre l'ecriture, cit., pp. 64-65.

47 D. Sartori, Volver a pensar, con otras, en lo que hacemos, cit.

48 Diotima, La Festa è qui, Nàpols, Liguri, 2012, p. 1.

49 Ibid. 